\begin{tabular}{|c|c|}
\hline Title & Further applications of classical amide coupling reagents: Microwave assisted esterification on solid phase \\
\hline Author(s) & T akay ama, Risa; Hayakawa, Shun; Hinou, Hiroshi; A Ibericio, Fernando; Garcia Martin, Fayna \\
\hline Citation & $\begin{array}{l}\text { Journal of peptide science, 24(8-9), UNSP e3111 } \\
\text { https://doi.org/10.1002/psc.3111 }\end{array}$ \\
\hline Issue Date & 201808 \\
\hline Doc URL & http:/hdl.handle.net/2115/75071 \\
\hline Rights & $\begin{array}{l}\text { This is the peer reviewed version of the following article: Journal of Peptide Science V olume24, Issue8-9, A ugust- } \\
\text { September 2018, e3111, which has been published in final form at https://doi.org/10.1002/psc.3111. This article may } \\
\text { be used for non-commercial purposes in accordance with Wiley Terms and Conditions for Self-A rchiving. }\end{array}$ \\
\hline Type & article (author version) \\
\hline Additional Information & There are other files related to this item in HUSCAP. Check the above URL. \\
\hline File Information & 01_PaperEsterification_JPepSci-2.pdf \\
\hline
\end{tabular}

Instructions for use 


\title{
Further applications of classical amide coupling reagents: microwave-assisted esterification on solid- phase
}

Risa Takayama ${ }^{1}$, Shun Hayakawa ${ }^{1}$, Hiroshi Hinou ${ }^{1,2,3}$, Fernando Albericio ${ }^{4,5}$ and Fayna Garcia-Martin ${ }^{*, 1,2}$.

1. Graduate School of Life Science, Hokkaido University, N21, W11, Kita-ku, Sapporo 0010021, Japan

2. Faculty of Advanced Life Science, Hokkaido University, N21, W11, Kita-ku, Sapporo 0010021, Japan

3. Medicinal Chemistry Pharmaceuticals, Company Ltd., N21, W12, Kita-ku, Sapporo 001-0021, Japan

4. Department of Organic Chemistry and CIBER-BBN, Networking Centre on Bioengineering, Biomaterials and Nanomedicine, University of Barcelona, Barcelona 080028, Spain

5. School of Chemistry and Physics, University of KwaZulu-Natal, Durban 4001, South Africa

* corresponding author: faynagm@sci.hokudai.ac.jp

\begin{abstract}
Ester linkage(s) is a key chemical connector in organic chemistry, including natural products, peptides, and synthetic polymers. We herein describe a straightforward method for the efficient formation of ester linkage(s) on solidphase. This method simply involves the use of amide coupling reagents under microwave irradiation. The robustness of this method relies on the use of classical solid-phase coupling reagents, heating by microwave irradiation, and a short time period, which results in high yields and the minimization of racemization.
\end{abstract}

\section{INTRODUCTION}

At glance, peptide synthesis may be described as an acylation step that is performed by coupling reagents and is followed by the removal of a protecting group. Both steps are repeated as many times as necessary until the completion of the target sequence. Finally, a global deprotection step is conducted in order to remove side-chain protecting groups together with a cleavage step of the peptide from the resin in the case of a solid-phase strategy.[1] In this context, the development of a large number of new efficient coupling reagents has been witnessed in recent years. Especially in the solid-phase synthesis, advances have been achieved in obtaining novel and more efficient reagents for amide coupling.[2-5] However, also ester bond is an important structural unit that serves as key component in a variety of applications and roles.[6] Ester bonds can be present in the middle of the peptide backbone, in so-called depsipeptides. This type of fascinating peptides has ester(s) incorporated either forming lactones or 
within a linear sequence. A large number of microbial non-ribosomal peptides that have been attracting increasing interest as therapeutic agents are depsipeptides.[7,8] A recent example is Teixobactin, a new class of antibiotic that has been the focus of research due to its high potency against Gram-positive bacteria in vitro. $[9,10]$

Depsipeptide chemical synthesis is not only attracting attention for producing naturally ester occurring peptides, but also as an approach for the synthesis of challenging peptides, namely, the $O$-acyl isopeptide method developed by Professor Kiso et al. This methodology takes advantage of the presence of an ester bond in the sequence that breaks inter- and intrachain associations, which are the main source of synthetic difficulties, and, thus, facilitates stepwise elongation. It consists of the addition of ester linkage(s) to the sequence through the side chain of Ser or Thr and continued elongation of the peptide through $\beta$ hydroxy function (O-acyl isopeptides). Once the full sequence is achieved and the depsipeptide is purified, a simple mild basic treatment favors the $O$ to $N$-acyl rearrangement, thereby rendering the desired full amide peptide.[11-14]

The safe formation of an ester bond is also key for ensuring the quality of $C$ terminal acid peptides when a hydroxyl base resin is used. The ester bond is regularly formed as the first linkage between an $\mathrm{N}$-protected amino acid and hydroxymethyl polymers, as when employing the widely used Wang linker resin.[15]

At present, the synthesis of depsipeptides or ester-containing peptides is currently not straightforward mainly due to the lower reactivity of the alcohol than that of the amine group. Several strategies have been conducted for the addition of ester linkage(s) to solid supports. One of the most common strategies to activate carboxylic acid is through a symmetrical anhydride, prepared with carbodiimide reagents and catalyzed by dimethylaminopyridine (DMAP).[16-20] This method works well for regular amino acids, but is not the most appropriate when attaching racemization-prone amino acid derivatives.[21,22] Under more challenging conditions, MSNT (1-(Mesitylene-2-sulfonyl)-3-nitro-1,2,4-triazole) is the reagent of choice to reduce enantiomerization.[21,23] The main limitation of effective MSNT is its cost and tedious protocol, which includes the use of hazardous $\mathrm{CH}_{2} \mathrm{Cl}_{2}$ as a solvent. It is important to note that commonly used methods, such as carbodiimides in the presence of hydroxybenzotriazole, OxymaPure, or uronium salts including HBTU (N-[(1H-benzotriazol-1-yl)(dimethylamino)methylene]-N-methylmethanaminium hexafluorophosphate $\mathrm{N}$-oxide) and COMU (1-[(1-(cyano-2-ethoxy-2-oxoethylideneaminooxy)dimethylamino-morpholinomethylene)] methanaminium hexafluorophosphate) [24-26] has not found applicability to ester formation by solid-phase synthesis.

One of the latest revolutions in this field is the automatic synthesizer and the use of microwave to accelerate synthesis and obtain higher quality products.[27-32] Classical and novel amide coupling reagents have been employed under microwave conditions with favorable outcomes.[33-35] In spite of the extensive 
efforts used to adjust non-heating methods in the microwave system, amide coupling has been the only focus of research, while other linkages on peptides have not been investigated. Common ester bonding on solid-phase synthesis is generally performed without microwave assistance and includes reagents other than the amide coupling option. $[16,18,21-23,36]$

As described above, a method to construct peptides including esters is a major chemical issue of interest. A novel strategy needs to include an efficient, fast, straightforward protocol that uses common reagents with the possibility of adaptation to automatic systems. To date, the microwave-assisted reaction used for solid-phase peptide synthesis has not yet been adapted to ester linkage, which may contribute to advances in the field.

\section{RESULTS \& METHODS}

An ester bond is an important structural unit that serves as key component in a number of applications.[6] Novel fast peptide synthesis using microwave irradiation also requires a direct protocol to achieve on-resin esterification in a robust and straightforward manner. As an alternative, we propose the use of conventional amide coupling reagents, such as HBTU or COMU, with the assistance of microwave irradiation as a direct route to obtain ester linkage(s) on a solid support for the first residue or esterification peptide backbone elongation as an intra-linkage.

A number of issues need to be addressed when investigating the efficiency of employing common amide coupling reagents for on-resin esterification: obtaining a high conversion rate of the reaction; investigation of the enantiomerization of the $C$-terminal ester under this protocol; confirmation of the universal use of this protocol by incorporating an intramolecular ester bond with a novel adapted protocol.

In order to verify the use of amide coupling reagents as esterification agents, Phe and His residues were initially incorporated onto Wang linker resin under a number of different conditions. Table 1 summarizes the loading obtained after attachment of the first amino acid.

When incorporating Fmoc-Phe-OH and Fmoc-His(Trt)-OH onto Wang linker resin, the highest rates were achieved using the symmetrical anhydride approach (\#3 and \#4) and similar results were obtained for MSNT (\#1 and \#2). Surprisingly, the loading obtained with MSNT coupling reagent was satisfactory but lower than expected. In order to confirm the superior performance of the DIC protocol, we also tested the Ala residue. The results obtained showed that the coupling of Fmoc-Ala-OH was lower with the MSNT approach than with the DIC/DMAP method $(0.74 \mathrm{mmol} / \mathrm{gr}$ resin $v s 0.98 \mathrm{mmol} / \mathrm{gr}$ resin) and the longer coupling time for MSNT did not improve the yield. 
The classical HBTU method adapted for esterification under MW conditions was performed using single or double coupling and different times. As shown in Table 1 , coupling for $10 \mathrm{~min}(\# 5)$ and double coupling for $10 \mathrm{~min}(\# 6)$ provided ester linkages. An adequate higher yield was obtained by double coupling for $20 \mathrm{~min}$ under microwave irradiation (\#7 and \#8). Double coupling assisted by microwave irradiation was also attempted for the novel coupling cocktail based on COMU/Oxyma. The first amino acid for Phe and His (\#9 and \#10) was incorporated with a high yield that was similar to established esterification methods.

According to the above results, amide coupling reagents by heating under microwave irradiation are also suitable for incorporating the first amino acid as an ester. It currently remains unclear whether this method is suitable for amino acids that are prone to racemization as His or Cys residues.[37-39] Therefore, we investigated the enantiomerisation ratio[40] using classical on-resin esterification reagents and the novel adapted method based on HBTU. We selected the His residue in the present study because $\pi$-nitrogen at the imidazole ring may abstract hydrogen at $\mathrm{Ca}$ under basic conditions, thereby promoting racemization. We had concern about HBTU/HOBt and COMU/Oxyma microwave-assisted methods because the ratio of racemization may increase at higher temperatures and also in the presence of a base. [39,41,42]. Therefore, we employed the linkage of His as the first amino acid, and measured racemization based on the RP-UPLC area of the model peptide Fmoc-Gly-Phe-D/L-His-OH. The results obtained are summarized in Table 2 . The highest racemization ratio was obtained using COMU reagent (\#14) followed by carbodiimide catalyzed with DMAP (\#12). [21,43] In case of HBTU (\#13) and MSNT (\#11) methods, the racemisation is reduced to $16 \%$ and $11 \%$, respectively. Even if racemization was not completely suppressed by the HBTU conditions for the His residue, the results obtained showed the facile incorporation of the first residue in a high yield and the racemization ratio was similar to those with expensive MSNT reagent. The HBTU/HOBt method represents a good compromise between a high yield and low racemization.

After concluding that the amide classical method under microwave irradiation is suitable for esterification of the first linkage on a solid support, we investigated whether to extend the application to all types of ester-based peptides. Ester intramolecular linkage in peptides is a common connection on natural peptides as well as an artificial approach to obtaining difficult peptides through " $O-N$ intramolecular acyl migration". The latter strategy was developed as a novel method $[11,14,44]$ to obtain previously inaccessible peptides due to the incomplete solvation of the peptidyl-resin complex during elongation.[45]

A general strategy to synthesize depsipeptides includes the synthesis of a unique building block of two amino acids including the intermediate ester, followed by its 
incorporation under traditional methods.[46] Another general approach is the direct formation of an ester linkage by adding an alternative reagent cocktail to that for amide formation, which generally needs a longer reaction time.[6,47-49] In order to test the scope of the present method, we attempted to synthesize a depsipeptide using the HBTU/HOBt protocol for amide and ester linkages. We selected HBTU because it is a good alternative for high loading with low racemization.

In order to investigate the suitability of the new method for other ester linkages, we attempted to synthesize the depsipeptide $\mathrm{H}-\mathrm{Ser}(\mathrm{Ac}-\mathrm{Val}-\mathrm{Val}-)$-Val-Val- $\mathrm{NH}_{2}$ (1) as a model compound with an ester linkage between hydroxyl side chain of Ser3 and consecutive Val. In a previous study by Sohma et al. [50], synthesis of the parental peptide -all amide bonds- by the standard SPPS method afforded a high rate of undesired Fmoc unprotected peptide fragments. Only the $\mathrm{O}$-acyl isopeptide method successfully achieved the desired peptide; however, they observed a racemization of $0.8 \%$ under DIC/DMAP conditions.[50]

In the present study, we focused on the synthesis of the depsipeptide 1 (Schema 1) based on HBTU/HOBt under microwave irradiation for the amide and ester reactions.

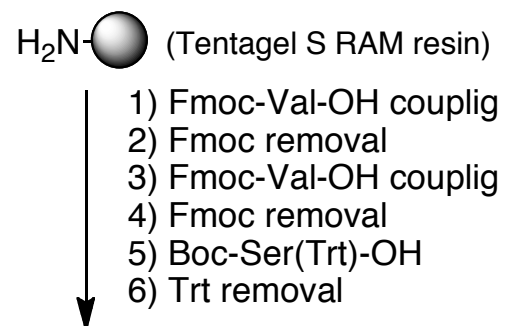

2) Fmoc removal

3) Fmoc-Val-OH couplig

4) Fmoc removal

5) Boc-Ser(Trt)-OH

6) Trt removal

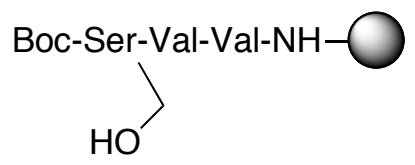
7) Fmoc-Val-OH couplig
8) Fmoc removal
9) Fmoc-Val-OH couplig
10) Fmoc removal
11) Acetylation

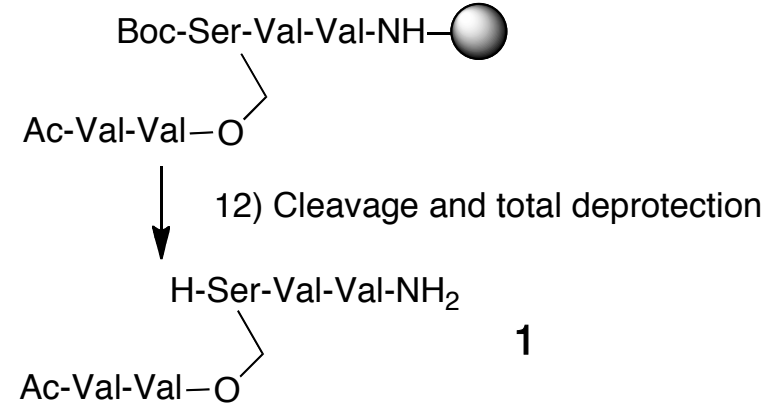

Schema 1. Synthesis of depsipeptide 1. 
After synthesis, the depsipeptide was cleaved and analyzed. We obtained a final compound characterized by RP-HPLC and MALDI-TOF (Figure S5). The HPLC chromatogram and mass spectrum confirmed that the main peak corresponded to the desired depsipeptide without racemization. The lyophilized sample afforded a $50.5 \%$ yield (over 7 steps from the original resin, with an average of $90 \%$ per step). Thus, this method may be appropriate for depsipeptide synthesis in a direct, fast, and uncomplicated manner.

\section{CONCLUSION}

We herein established a novel protocol for esterification based on classical amide coupling reagents assisted by microwave irradiation without the need for additional coupling reagents and/or changing the peptide synthesis instrument system. We employed the most demanding Wang resin as a model, and acylation by HBTU/HOBt exhibited an excellent compromise between a good yield and acceptable racemization.

For automatic synthesis, the benefit of this protocol is envisioned as it may avoid any manual synthesis from the first residue without the need to pause the synthetic process in order to incorporate intrapeptide ester linkages. This methodology provides access to more peptides and depsipeptides in an efficient, cheaper, and fast manner.

\section{SUPPORTING INFORMATION}

Supporting information may be found in the online version of this article.

\section{ACKNOWLEDGMENTS}

Our greatest acknowledgment is of Prof. Shin-Ichiro Nishimura for his continuous support and encouragement. The donation of COMU reagent from Luxembourg Bio Technologies, Ltd. was greatly appreciated. This work was financially supported by JSPS Wakate B KAKENHI Grant 24710242 and funding from Naito Foundation to F.G.-M..

Jaradat DMM. Thirteen Decades of Peptide Synthesis: Key

Developments in Solid Phase Peptide Synthesis and Amide Bond Formation Utilized in Peptide Ligation. Amino Acids 2018; 50: 39-68; DOI:10.1007/s00726-017-2516-0.

2 Albericio F. Developments in Peptide and Amide Synthesis. Curr Opin Chem Biol 2004; 8: 211-221; DOI:10.1016/j.cbpa.2004.03.002.

3 Montalbetti CAGN, Falque V. Amide Bond Formation and Peptide Coupling. Tetrahedron 2005; 61: 10827-10852; DOI:10.1016/j.tet.2005.08.031.

4 Valeur E, Bradley M. Amide Bond Formation: Beyond the Myth of Coupling Reagents. Chem Soc Rev 2009; 38: 606-631; DOI:10.1039/b701677h. 
DOI:10.1021/cr100048w.

6 Tsakos M, Schaffert ES, Clement LL, Villadsen NL, Poulsen TB. Ester Coupling Reactions - an Enduring Challenge in the Chemical Synthesis of Bioactive Natural Products . Nat Prod Rep 2015; 32 : 605-632; DOI:10.1039/C4NP00106K.

7 Sivanathan S, Scherkenbeck J. Cyclodepsipeptides: a Rich Source of Biologically Active Compounds for Drug Research. Molecules 2014; 19: 12368-12420; DOI:10.3390/molecules190812368.

$8 \quad$ Kitagaki J, Shi G, Miyauchi S, Murakami S, Yang Y. Cyclic Depsipeptides as Potential Cancer Therapeutics. Anticancer Drugs 2015; 26: 259-271; DOI:10.1097/CAD.0000000000000183.

9 Ling LL, Schneider T, Peoples AJ, Spoering AL, Engels I, Conlon BP, Mueller A, Schäberle TF, Hughes DE, Epstein S, Jones M, Lazarides L, Steadman VA, Cohen DR, Felix CR, Fetterman KA, Millett WP, Nitti AG, Zullo AM, Chen C, Lewis K. A New Antibiotic Kills Pathogens Without Detectable Resistance. Nature 2015; 517: 455-459;

DOI:10.1038/nature14098.

10 Nussbaum von F, Süssmuth RD. Multiple Attack on Bacteria by the New Antibiotic Teixobactin. Angew Chem Int Ed Engl 2015; 54: 66846686; DOI:10.1002/anie.201501440.

11 Sohma Y, Hayashi Y, Skwarczynski M, Hamada Y, Sasaki M, Kimura $\mathrm{T}$, Kiso Y. O-N Intramolecular Acyl Migration Reaction in the Development of Prodrugs and the Synthesis of Difficult SequenceContaining Bioactive Peptides. Biopolymers 2004; 76: 344-356; DOI:10.1002/bip.20136.

12 Taniguchi A, Sohma Y, Kimura M, Okada T, Ikeda K, Hayashi Y, Kimura T, Hirota S, Matsuzaki K, Kiso Y. "Click Peptide" Based on the "O-Acyl Isopeptide Method": Control of a Beta1-42 Production From a Photo-Triggered a Beta1-42 Analogue. J Am Chem Soc 2006; 128: 696-697; DOI:10.1021/ja057100v.

13 Coin I, Dölling R, Krause E, Bienert M, Beyermann M, Sferdean CDA, Carpino LA. Depsipeptide Methodology for Solid-Phase Peptide Synthesis: Circumventing Side Reactions and Development of an Automated Technique via Depsidipeptide Units. J Org Chem 2006; 71: 6171-6177; DOI:10.1021/jo060914p.

14 Coin I. The Depsipeptide Method for Solid-Phase Synthesis of Difficult Peptides. J Pept Sci 2010; 16: 223-230; DOI:10.1002/psc.1224.

$15 \quad$ Wang SS. P-Alkoxybenzyl Alcohol Resin and PAlkoxybenzyloxycarbonylhydrazide Resin for Solid Phase Synthesis of Protected Peptide Fragments. J Am Chem Soc 1973; 95: 13281333.

16 Neises B, Steglich W. Simple Method for the Esterification of 
Carboxylic Acids. Angew Chem Int Ed Engl 1978; 17: 522-524; DOI:10.1002/anie.197805221.

17 Dryland A, Sheppard RC. Peptide Synthesis. Part 8. a System for Solid-Phase Synthesis Under Low Pressure Continuous Flow Conditions. J Chem Soc Perk T 11986; 0: 125-137; DOI:10.1039/p19860000125.

18 Nielsen J, Lyngs LO. Combinatorial Solid-Phase Synthesis of Balanol Analogues. Tetrahedron Lett 1996; 37: 8439-8442; DOI: 10.1016/0040-4039(96)01913-2.

19 Albericio F, Bryman LM, García J, Michelotti EL, Nicolás E, Tice CM. Synthesis of a Sulfahydantoin Library. J Comb Chem 2001; 3: 290300.

20 Tulla-Puche J, Bayó-Puxan N, Moreno JA, Francesch AM, Cuevas C, Alvarez M, Albericio F. Solid-Phase Synthesis of Oxathiocoraline by a Key Intermolecular Disulfide Dimer. J Am Chem Soc 2007; 129: 5322-5323; DOI:10.1021/ja0686312.

21 Blankemeyer-Menge B, Nimtz M, Frank R. An Efficient Method for Anchoring Fmoc-Anino Acids to Hydroxyl-Functionalised Solid Supports. Tetrahedron Lett 1990; 31: 1701-1704.

22 Topping RJ, Nuiry I, Mastriona J, Moss JA. Optimized "Inverse Activation" Methodology for Esterification of Hydroxyl-Functionalized Resins. Tetrahedron Letters 2008; 49: 2907-2910; DOI:10.1016/j.tetlet.2008.03.029.

23 Harth-Fritschy E, Cantacuzène D. Esterification of 9Fluorenylmethoxycarbonyl-Glycosylated Serine and Cysteine Derivatives with an Hydroxymethyl Resin. J Pept Res 1997; 50: 415420.

24 El-Faham A, Funosas RS, Prohens R, Albericio F. COMU: a Safer and More Effective Replacement for Benzotriazole-Based Uronium Coupling Reagents. Chem. Eur. J. 2009; 15: 9404-9416; DOI:10.1002/chem.200900615.

25 Subirós-Funosas R, Prohens R, Barbas R, El-Faham A, Albericio F. Oxyma: an Efficient Additive for Peptide Synthesis to Replace the Benzotriazole-Based HOBt and HOAt with a Lower Risk of Explosion. Chem. Eur. J. 2009; 15: 9394-9403; DOI:10.1002/chem.200900614.

26 Subirós-Funosas R, Acosta GA, El-Faham A, Albericio F. Microwave Irradiation and COMU: a Potent Combination for Solid-Phase Peptide Synthesis. Tetrahedron Letters 2009; 50: 6200-6202; DOI:10.1016/j.tetlet.2009.08.117.

27 Merrifield RB. Automated Synthesis of Peptides. Science 1965; 150: 178-185; DOI:10.1126/science.150.3693.178.

28 Sabatino G, Papini AM. Advances in Automatic, Manual and Microwave-Assisted Solid-Phase Peptide Synthesis. Current opinion in drug discovery \& development 2008; 11: 762-770. 
Vanier GS. Microwave-Assisted Solid-Phase Peptide Synthesis Based on the Fmoc Protecting Group Strategy (CEM). Methods Mol Biol 2013; 1047: 235-249; DOI:10.1007/978-1-62703-544-6_17.

$30 \quad$ Malik L, Jensen KJ. Microwave-Assisted Solid-Phase Peptide Synthesis Using the Biotage Syro Wave ${ }^{\mathrm{TM}}$. In, Vol. 1047. Methods in Molecular Biology, 2013; 225-234; DOI:10.1007/978-1-62703-5446_16.

31 Mäde V, Els-Heindl S, Beck-Sickinger AG. Automated Solid-Phase Peptide Synthesis to Obtain Therapeutic Peptides. Beilstein J Org Chem 2014; 10: 1197-1212; DOI:10.3762/bjoc.10.118.

32 Collins JM, Porter KA, Singh SK, Vanier GS. High-Efficiency Solid Phase Peptide Synthesis (HE-SPPS). Org Lett 2014; 16: 940-943; DOI:10.1021/ol4036825.

33 Yu HM, Chen ST, Wang KT. Enhanced Coupling Efficiency in SolidPhase Peptide Synthesis by Microwave Irradiation. J Org Chem 1992; 57: 4781-4784; DOI:10.1021/j000044a001.

34 Matsushita T, Hinou H, Kurogochi M, Shimizu H, Nishimura S-I. Rapid Microwave-Assisted Solid-Phase Glycopeptide Synthesis. Org Lett 2005; 7: 877-880; DOI:10.1021/ol0474352.

$35 \quad$ Murray JK, Aral J, Miranda LP. Solid-Phase Peptide Synthesis Using Microwave Irradiation. Methods Mol Biol 2011; 716: 73-88;

DOI:10.1007/978-1-61779-012-6_5.

36 Albericio F, Barany G. Improved Approach for Anchoring Na-9Fluorenylmethyloxycarbonylamino Acids as P-Alkoxybenzyl Esters in Solid-Phase Peptide Synthesis. Int J Pept Prot Res 1985; 26: 92-97; DOI:10.1111/j.1399-3011.1985.tb03182.x.

37 Han Y, Albericio F, Barany G. Occurrence and Minimization of Cysteine Racemization During Stepwise Solid-Phase Peptide Synthesis. J Org Chem 1997; 62: 4307-4312.

38 Angeletti RH, Bibbs L, Bonewald LF, Fields GB, Kelly JW, McMurray JS, Weintraub ST. Analysis of Racemization During "Standard" Solid Phase Peptide Synthesis: A Multicenter Study In Techniques in Protein Chemistry VIII [10th Symposium of the Protein Society],1996, Marshak DR (ed.). Academic: SanDiego, CA, 1997; 875-890. DOI:10.1016/S1080-8914(97)80084-1.

39 Palasek SA, Cox ZJ, Collins JM. Limiting Racemization and Aspartimide Formation in Microwave-Enhanced Fmoc Solid Phase Peptide Synthesis. J Pept Sci 2007; 13: 143-148; DOI:10.1002/psc.804.

40 Benoiton NL. Sometimes It Is Neither a Racemisation nor an Epimerisation but an Enantiomerisation. A Plea for Preciseness in the Use of Terms Describing Stereomutations That Occur in Peptide Synthesis. Int J Pept Prot Res 1994; 44: 399-400.

41 Bacsa B, Horváti K, Bõsze S, Andreae F, Kappe CO. Solid-Phase 
Synthesis of Difficult Peptide Sequences at Elevated Temperatures: a Critical Comparison of Microwave and Conventional Heating Technologies. J Org Chem 2008; 73: 7532-7542; DOI:10.1021/j08013897.

42 Hibino H, Miki Y, Nishiuchi Y. Synthesis and Application of Na-FmocNח-4-Methoxybenzyloxymethylhistidine in Solid Phase Peptide Synthesis. J Pept Sci 2012; 18: 763-769; DOI:10.1002/psc.2464.

43 Atherton E, Benoiton NL, Brown E, Sheppard RC, Williams BJ. Racemisation of Activated, Urethane-Protected Amino-Acids by PDimethyl-Aminopyridine. Significance in Solid-Phase Peptide Synthesis. Chem. Commun. 1981; 0: 336-337;

DOI:10.1039/c39810000336.

44 Horikawa M, Shigeri Y, Yumoto N, Yoshikawa S, Nakajima T, Ohfune Y. Syntheses of Potent Leu-Enkephalin Analogs Possessing BetaHydroxy-Alpha,Alpha-Disubstituted-Alpha-Amino Acid and Their Characterization to Opioid Receptors. Bioorg Med Chem Lett 1998; 8: 2027-2032.

45 Bedford J, Hyde C, Johnson T, Jun W, Owen D, Quibell M, Sheppard RC. Amino Acid Structure and "Difficult Sequences" in Solid Phase Peptide Synthesis. Int J Pept Prot Res 1992; 40: 300-307.

$46 \quad$ Nguyen MM, Ong N, Suggs L. A General Solid Phase Method for the Synthesis of Depsipeptides. Org Biomol Chem 2013; 11: 1167-1170; DOI:10.1039/c2ob26893k.

47 Bayó-Puxan N, Tulla-Puche J, Albericio F. Oxathiocoraline: Lessons to Be Learned From the Synthesis of Complex N-Methylated Depsipeptides. Eur J Org Chem 2009; 2957-2974; DOI:10.1002/ejoc.200900259.

48 Jad YE, Acosta GA, Naicker T, Ramtahal M, El-Faham A, Govender T, Kruger HG, la Torre de BG, Albericio F. Synthesis and Biological Evaluation of a Teixobactin Analogue. Org Lett 2015; 17: 6182-6185; DOI:10.1021/acs.orglett.5b03176.

49 Giltrap AM, Dowman LJ, Nagalingam G, Ochoa JL, Linington RG, Britton WJ, Payne RJ. Total Synthesis of Teixobactin. Org Lett 2016; 18: 2788-2791; DOI:10.1021/acs.orglett.6b01324.

50 Sohma Y, Sasaki M, Hayashi Y, Kimura T, Kiso Y. Novel and Efficient Synthesis of Difficult Sequence-Containing Peptides Through O-N Intramolecular Acyl Migration Reaction of O-Acyl Isopeptides. Chem Commun 2004; 124-125; DOI:10.1039/b312129a. 
Table 1. Conversion rate of Wang linker resin (initial loading, $1.2 \mathrm{mmol} / \mathrm{gr}$ resin) under different esterification conditions when attaching Fmoc-Phe-OH and Fmoc-His(Trt)-OH

\begin{tabular}{|c|c|c|c|c|c|c|}
\hline Reagent $^{\mathrm{a}}$ & Solvent & Time & Temp. & \# & Fmoc-AA-OH & Loading $^{d}$ \\
\hline \multirow{2}{*}{ MSNT (4.0 eq.), NMI (8.0 eq.) ${ }^{\text {b }}$} & \multirow{2}{*}{$\mathrm{CH}_{2} \mathrm{Cl}_{2}$} & \multirow{2}{*}{$30 \min$} & \multirow{2}{*}{ r.t. } & 1 & Phe & 1.08 \\
\hline & & & & 2 & His & 0.96 \\
\hline \multirow{2}{*}{ DIC (3.5 eq.), DMAP (0.1 eq. $)^{b}$} & \multirow{2}{*}{$\begin{array}{l}\mathrm{CH}_{2} \mathrm{Cl}_{2} / \\
\operatorname{DMF}(9: 1)\end{array}$} & \multirow{2}{*}{ Overnight } & \multirow{2}{*}{ r.t. } & 3 & Phe & 1.14 \\
\hline & & & & 4 & His & 1.08 \\
\hline $\begin{array}{l}\text { HBTU (6.0 eq.), HOBt }(6.0 \\
\text { eq.) DIEA ( } 8.0 \text { eq. })^{\text {b }}\end{array}$ & DMF & $10 \min ^{c}$ & $50^{\circ} \mathrm{C}$ & 5 & His & 0.69 \\
\hline $\begin{array}{l}\text { HBTU (6.0 eq.), HOBt ( } 6.0 \\
\text { eq.) DIEA ( } 8.0 \text { eq.) }\end{array}$ & DMF & $10 \min \times 2^{c}$ & $50^{\circ} \mathrm{C}$ & 6 & His & 0.76 \\
\hline \multirow{2}{*}{$\begin{array}{l}\text { HBTU (6.0 eq.), HOBt }(6.0 \\
\text { eq.) DIEA (8.0 eq. })^{\text {b }}\end{array}$} & \multirow{2}{*}{ DMF } & \multirow{2}{*}{$20 \min \times 2^{c}$} & \multirow{2}{*}{$50^{\circ} \mathrm{C}$} & 7 & Phe & 0.88 \\
\hline & & & & 8 & His & 0.91 \\
\hline \multirow{2}{*}{$\begin{array}{l}\text { COMU (6.0 eq.), Oxyma (6.0 } \\
\text { eq.) DIEA (8.0 eq.) }\end{array}$} & \multirow{2}{*}{ DMF } & \multirow{2}{*}{$20 \min \times 2^{c}$} & \multirow{2}{*}{$50^{\circ} \mathrm{C}$} & 9 & Phe & 1.02 \\
\hline & & & & 10 & His & 1.06 \\
\hline
\end{tabular}

a) Use of $30 \mathrm{mg}$ of solid support for each assay. Details of reaction conditions are in the Experimental Section in Supporting Information (S.I.)

b) Each reaction was performed in duplicate. Results were averaged.

c) The coupling reaction was assisted by MW energy $\left(0-50 \mathrm{~W} ; 50^{\circ} \mathrm{C}\right)$.

d) Loading (substituted $\mathrm{mmol} / \mathrm{gr}$ resin) was calculated by the Fmoc photometric test (fluorene group UV at $290 \mathrm{~nm}$ ). Each UV measurement was performed in triplicate, and results were averaged.

Table 2. Conversion and racemization ratio of His residue incorporated onto Wang linker resin under different esterification conditions.

\begin{tabular}{|c|c|c|c|c|}
\hline$\#$ & Reagent $^{\mathrm{a}}$ & Solvent & Time & D-His ratio ${ }^{\mathrm{d}}$ \\
\hline 11 & $\begin{array}{l}\text { MSNT (4.0 eq.), } \\
\text { NMI (8.0 eq.) }\end{array}$ & $\mathrm{CH}_{2} \mathrm{Cl}_{2}$ & $1 \mathrm{~h}$ & $10.74 \%$ \\
\hline 12 & $\begin{array}{l}\text { DIC (3.5 eq.), } \\
\text { DMAP (0.1 eq.) }\end{array}$ & $\mathrm{CH}_{2} \mathrm{Cl}_{2} / \mathrm{DMF}(9: 1)$ & Overnight & $28.62 \%$ \\
\hline 13 & $\begin{array}{l}\text { HBTU (6.0 eq.), } \\
\text { HOBt (6.0 eq.) } \\
\text { DIEA (8.0 eq.) }\end{array}$ & DMF & $20 \min \times 2^{c}$ & $15.99 \%$ \\
\hline 14 & $\begin{array}{l}\text { COMU (6.0 eq.), } \\
\text { Oxyma (6.0 eq.) } \\
\text { DIEA (8.0 eq.) }\end{array}$ & DMF & $20 \min \times 2^{c}$ & $26.45 \%$ \\
\hline
\end{tabular}

a) Reaction conditions details are in the Experimental Section in Supporting Information (S.I.)

b) Use of $30 \mathrm{mg}$ of solid support.

c) The reaction time was 20 min assisted by MW energy $\left(0-50 \mathrm{~W} ; 50{ }^{\circ} \mathrm{C}\right)$.

d) Racemization ratio calculated by RP-UPLC area of Fmoc-Gly-Phe-His-OH and Fmoc-GlyPhe-his-OH. 